\title{
Bioaccumulation of arsenic compounds in aquacultural clams (Meretrix lusoria) and assessment of potential carcinogenic risks to human health by ingestion
}

\author{
Chen-Wuing Liu ${ }^{\text {a,* }}$, Ching-Ping Liang ${ }^{\text {a,b }}$, Kao-Hung Lin ${ }^{c}$, Cheng-Shin Jang ${ }^{d}$, \\ Sheng-Wei Wang ${ }^{a}$, Yung-Kay Huang ${ }^{e}$, Yu-Mei Hsueh ${ }^{\mathrm{f}}$ \\ a Department of Bioenvironmental Systems Engineering, National Taiwan University, Taipei 106, Taiwan, ROC \\ ${ }^{\mathrm{b}}$ Department of Environmental Engineering and Science, Foo-Yin University, Kaoshiung 831, Taiwan, ROC \\ ${ }^{\mathrm{c}}$ Sustainable Environment Research Center, National Cheng Kung University, Tainan 701, Taiwan, ROC \\ ${ }^{\mathrm{d}}$ Department of Leisure and Recreation Management, Kainan University, Luzhu, Taoyuan, Taiwan 338, Republic of China \\ ${ }^{\mathrm{e}}$ Graduate Institute of Medical Sciences, Taipei Medical University, Taipei 110, Taiwan, ROC \\ ${ }^{\mathrm{f}}$ Department of Public Health, School of Medicine, Taipei Medical University, Taipei 110, Taiwan, ROC
}

Received 30 May 2006; received in revised form 10 April 2007; accepted 13 April 2007

Available online 29 May 2007

\begin{abstract}
This study surveyed the total arsenic (As) and As species contents in clams (Meretrix lusoria) farmed in areas of hyperendemic blackfoot disease (BFD) in southwestern Taiwan. Total As and As species in sediment and pond water were also analyzed to examine the bioaccumulation of As in clams in their exposure environment. Moreover, potential carcinogenic risks associated with the ingestion of As in aquacultural clams were evaluated probabilistically. The average total As contents in medium-sized and small clams were 7.62 and $10.71 \mu \mathrm{g} / \mathrm{g}$ (dry wt), respectively. The content of the As species in this study was approximately $61 \%$ of the total As content. The other unquantified As species are possibly arsenocholine, arsenosugar and arsenolipid. The average ratios of inorganic As contents to total As contents in clams ranged from $12.3 \%$ to $14.0 \%$ which are much higher than that found in the farmed oyster (Crassostrea gigas), indicating that humans may expose to larger quantities of inorganic As by ingesting the same amount of clam as oyster. Using different ingestion rates derived by the average consumption method and the questionnaire method, the estimated risks to human health associated with consuming clams from the BFD area ranging from slightly to largely exceed the standard target risk. Based on the estimation of the TR model, a $0.18 \mathrm{~g} /$ day-person of the safe ingestion rate of clams in the BFD region is recommended.
\end{abstract}

(C) 2007 Elsevier Ltd. All rights reserved.

Keywords: Arsenic species; Blackfoot disease; Bioaccumulation; Clam; Risk

\section{Introduction}

Clams (Meretrix lusoria) are favored species of edible shellfish in Taiwan. They are mainly cultured in plain areas of southwestern Taiwan. In the past few decades, blackfoot disease (BFD) prevailed in this region (Fig. 1) (Tseng, 1977). Extensive epidemiological evidence has proven that drinking groundwater with a high arsenic (As) content is

\footnotetext{
* Corresponding author. Tel.: +88622362 6480; fax: +886223639557.

E-mail address: lcw@gwater.agec.ntu.edu.tw (C.-W. Liu).
}

strongly associated with the occurrence of BFD (Ch'i and Blackwell, 1968). Recently, very few inhabitants in this region have drunk well water directly, but large amounts of groundwater have been utilized to farm fish and shellfish (Liao and Ling, 2003). Aquatic animals farmed in this region bioaccumulate large quantities of As. Numerous As species are present in aquatic organisms; they include arsenobetaine (AsB), monomethylarsonic acid (MMA), dimethylarsinic acid (DMA), arsenite (As(III)) and arsenate $(\mathrm{As}(\mathrm{V}))$. Inorganic $\mathrm{As}$ species are more toxic than methyl As species (Oremland and Stotlz, 2003). The US 


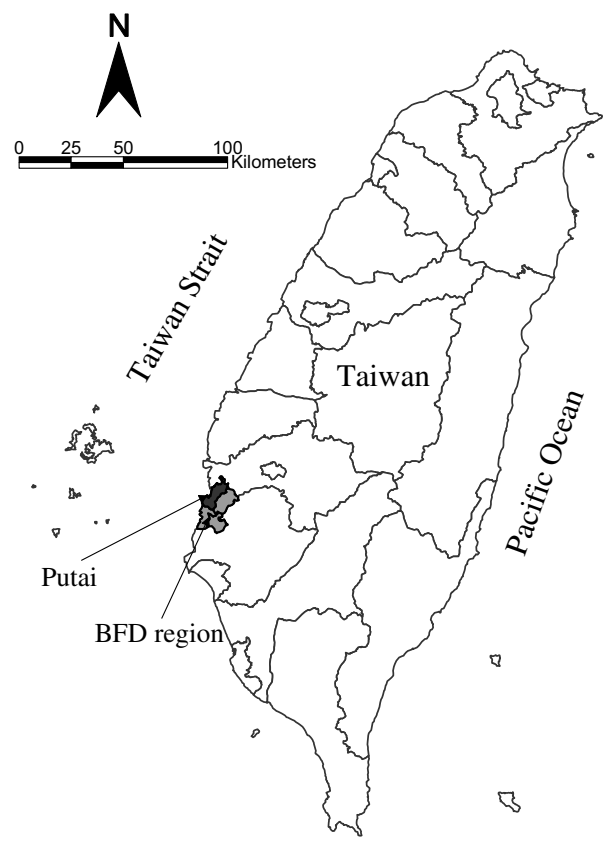

Fig. 1. Locations of the study site and BFD region.

EPA (1988) used the uptake of inorganic As by various seafood species to determine potential risks to human health. In recent years, several studies have assessed the risk of cancer associated with consuming aquatic products in coastal regions of southwestern Taiwan (Han et al., 2000; Liao and Ling, 2003; Liu et al., 2005, 2006).

Clams live at the interface between sandy sediment and water. Sediment in farmed ponds is full of organic material and can adsorb large quantities of heavy metals (Baudrimont et al., 2005), including As. Furthermore, clams are a sediment-dwelling animal and are cultivated in a semisalty aquatic environment. Seawater and groundwater are primary water resources in the farmed ponds. In the plain area of southwestern Taiwan, groundwater generally contains high level of As (Jang et al., 2006). When farmers pumped the groundwater to cultivate clams, the pond water and sediment were As-polluted. Hence, the clams bioaccumulated As from sediment and pond water. Many studies have indicated that the inorganic As level in clams exceeds those in other bivalves, such as oysters, scallops and others (Edmonds and Francesconi, 1993; Lai et al., 1999; Munoz et al., 1999, 2000). Clams and oysters in Taiwan represented $76.4 \%$ of the shellfish offered for sale in 2003. From 1994 to 2003, the number of clams as a percentage of the number of shellfish offered for sale increased from $32.6 \%$ to $43.9 \%$ while that of oysters declined from $41.4 \%$ to $32.4 \%$. However, previous investigations on this region have ignored the As content in clams and their potential risk to human health (Taiwan COA, 2003).

This study elucidates total As and As species contents in clams farmed in the BFD hyperendemic areas of southwestern Taiwan. Total As and As species in sediment and pond water also were analyzed to investigate bioaccumulation in clams in their natural environment. The total As and inor- ganic As contents in clams were compared with those in oysters presented in our previous study (Liu et al., 2006). The potential health risks associated with ingesting As contents in aquacultured clams were evaluated probabilistically. The data enabled the administrators to estimate human As dietary intakes, and provided a reference for acceptable daily intakes for the Food and Agricultural Organization (FAO) as well as the World Health Organization (WHO), so as to assess potential health hazards.

\section{Material and methods}

\subsection{Sampling and analysis}

Forty-seven clam samples were collected from 13 aquacultural ponds in the Putai county from December 2001 to March 2002 (Fig. 1). Each single clam represents an individual sample. Additionally, two pond water samples, two pond sediment samples and four clam samples (two from each pond) were collected from two aquaculture ponds to estimate the bio-concentration factor of total As content in clams from sediment and pond water in Putai. Sediment was extracted from the middle of the ponds $5 \mathrm{~cm}$ below the bottom. The water samples were collected in polyethylene containers, cleaned in $10 \%$ nitric acid and then rinsed using deionized water. Samples of clams, sediment and pond water from each pond were placed in polyethylene bags, and all were kept at $4{ }^{\circ} \mathrm{C}$ during transportation to the laboratory.

Total As and As species concentrations were determined. The procedures of analyzing $\mathrm{As}(\mathrm{III}), \mathrm{As}(\mathrm{V})$, MMA, DMA and AsB in all samples followed closely those used in our previous studies (Huang et al., 2003; Liu et al., 2006). However, only 26 clam samples were analyzed for AsB content. The AsB assay method was modified from that of Alberti et al. (1995), Dagnac et al. (1999) and Geiszinger et al. (1998). Our previous studies reported in detail the analytical procedures (Huang et al., 2003).

The accuracy of the procedure was validated by the analysis of the standard reference material (SRM) BCR 627 tuna tissue. The total As and DMA concentrations of SRM were $4.9 \pm 0.2 \mathrm{mg} / \mathrm{kg}$ and $1.8 \pm 0.1 \mu \mathrm{mol} / \mathrm{kg}$, consistent with the certified values of $4.8 \pm 0.3 \mathrm{mg} / \mathrm{kg}$ and $2.0 \pm 0.3 \mu \mathrm{mol} / \mathrm{kg}$, respectively. The instrument detection limits of total As, As(III), As(V), MMA, DMA and AsB were $0.2,0.4,0.2,0.4,0.3$ and $0.49 \mu \mathrm{g} / 1$, respectively. Samples were spiked with As species to determine the rate of recovery in every extraction step and laboratory procedure. Extraction recovery rates of $\mathrm{As}(\mathrm{III}), \mathrm{As}(\mathrm{V})$, MMA, DMA and AsB were $102.7 \pm 4.7 \%, 104.1 \pm 6.8 \%, 104.7 \pm 6.5 \%$, $98.0 \pm 7.1 \%$ and $97.7 \pm 6.4 \%$, respectively. Laboratory procedure recovery rates of total As, As(III), As $(\mathrm{V})$, MMA, DMA and AsB were $103.2 \pm 7.1 \%, 100.7 \pm 3.8 \%$, $97.2 \pm 4.0 \%, 104.9 \pm 4.6 \%, 97.2 \pm 4.0 \%$ and $97.9 \pm 4.7 \%$, respectively. Both extraction recovery rates and laboratory procedure recovery rates fell within the standard limits of 
90-110\%. A coefficient of variation (CV\%) was applied to test the reliability and was less than $5 \%$ for all experiments.

Boyden (1977) demonstrated that the accumulation of trace elements depends on their size. Growth dilution in mussels (Ünlü and Fowler, 1979) is such that the clam samples were divided into small (clam muscle $<3 \mathrm{~g}$ wet wt) and medium-sized (clam muscle $\geqslant 3 \mathrm{~g}$ and $<5 \mathrm{~g}$ wet wt). The numbers of small and medium-sized clam samples were 13 and 34, respectively. Analysis-of-variance (ANOVA) was adopted to identify statistical differences between total As and individual As species contents in clams based on the figure factor.

\subsection{Human health risk assessment}

The Risk Assessment Forum (US EPA, 1988) re-evaluated the carcinogenicity associated with ingesting inorganic As. The method for estimating the target cancer risk (TR) is supported in the US EPA Region III Risk-Based Concentration Table (US EPA, 2006). The risk associated with the carcinogenic effects of inorganic As is expressed as the excess probability of contracting cancer over a lifetime of 70 years. The model for estimating the target cancer risks (lifetime cancer risk) is as follows (US EPA, 1988, 1989, 2006).

$\mathrm{TR}=\frac{\mathrm{EFr} \times \mathrm{EDtot} \times \mathrm{SFI} \times \mathrm{MCS}_{\text {inorg }} \times \mathrm{CPSo}}{\mathrm{BWa} \times \mathrm{ATc}} \times 10^{-3}$

where TR represents the target cancer risk or the risk of cancer over a lifetime; EFr is the exposure frequency ( 350 days/year); EDtot is the exposure duration (30 years); SFI is the ingested mass of the edible portion of clam (g/day); $\mathrm{MCS}_{\text {inorg }}$ is the concentration of inorganic As species in the edible portion of clam $(\mu \mathrm{g} / \mathrm{g})$ wet wt; CPSo is the oral carcinogenic potency slope of inorganic arsenic (risk per $\mathrm{mg} / \mathrm{kg} / \mathrm{day})\left(1.5(\mathrm{mg} / \mathrm{kg} / \text { day })^{-1}\right)$; $\mathrm{BWa}$ is the body weight of a Taiwanese adult $(59.4 \mathrm{~kg}$ ) (Taiwan $\mathrm{DOH}$, 2006). An averaging time of 365 days/year for 76 years $(\mathrm{ATc}=76 \times 365$ days) was used to characterize the life time exposure of a Taiwanese in the calculation of cancer risk (Taiwan DOS, 2004). The mean ratio of edible clam muscle weight to total weight in this experiment was 0.2 . According to the Taiwanese Food Supply and Utilization Annual Report in 2003 (Taiwan COA, 2003), 31480 ton of clam were produced and 5 ton were exported. The Taiwanese population over the age of 4 years was 21.23 million in 2003 (Taiwan DOH, 2003). Consequently, the ingestion rate of edible portions of clam derived from the average consumption method was $0.812 \mathrm{~g} /$ day-person. For comparison, the daily ingestion rates of shell fish 4-14.5 g /day-person obtained from a questionnaire survey by Shih (2001) were also included to evaluate the TRs. The average water content in the clam samples was $83 \%$, which value was adopted to convert the dry weight to wet weight of inorganic As concentrations in clams. This work treated $\mathrm{MCS}_{\text {inorg }}$ in Eq. (1) probabilistically. The above analytical data were used to evaluate the potential risk of cancer in humans due to the consumption of clams in the BFD hyperendemic area. An estimated TR value of exceeding one millionth is typically considered to pose a potential threat to human health and an unacceptable risk.

\subsection{Uncertainty analysis}

The uncertainties associated with the exposure assumptions will be formally treated through the adoption of a Monte Carlo (MC) analysis (US EPA, 2001). Rather than using a deterministic approach, the range of possible values for each assumption will be defined by a probability density function and combined to give an overall likelihood of the probability of a certain exposure being encountered. @ Risk (Version4.5, Professional Edition, Palisade Crop.) software was used to analyze statistically the measured concentrations of inorganic As species in clams and to estimate parameters for the distribution of inorganic As species. A Kolmogorov-Smirnov (K-S) test was performed to determine the probability distributions that best fitted $\mathrm{MCS}_{\text {inorg }}$. Then, the MC technique was employed to generate the distribution of inorganic As contents in clams from the determined best-fit distributions of inorganic As concentrations. The resulting risk-based concentrations are compared to the literature-derived values to assess whether calculated concentrations pose an unacceptable risk of toxic effects.

\section{Results and discussion}

\subsection{Total As and As species contents in clams}

Table 1 presents mean and standard deviations of total As and various As species contents in clams. Fig. 2 shows their distributions using a box-and-whiskers plot. The mean total As content in all clams was $8.48 \mu \mathrm{g} / \mathrm{g}$ (dry wt) and the total As contents in the samples varied widely. The total As and $\mathrm{As}(\mathrm{V})$ contents in the small clams significantly exceeded those in the medium-sized clams $(p \leqslant 0.05)$. The As species analyzed herein represents approximately $61 \%$ of the total As contents in the clams. The other unquantified As species made up 39\% of the total As concentration in clam are possibly arsenocholine, arsenosugar and arsenolipid. The AsB content in clams exceeded that of the other As species in the study. The As(III) content in the clams was the second highest. The MMA and DMA contents are low. Notably, the mean ratio of inorganic As content to total As content in clams was $13.5 \%$ and varied highly in the medium-sized clams.

This study also investigated the relationship between As content and environment, including pond water and sediment. Table 2 presents total As and inorganic As contents in sediment, pond water and clams in two farmed ponds. The analyzed results reveal that high As content in sediment and pond water significantly enhance the bioaccumulation of As in clams. However, the As bioaccumulation in 
Table 1

Statistics concerning total As and various As species contents in clams

\begin{tabular}{lccc}
\hline As species & \multicolumn{3}{l}{ Concentration $($ mean $\pm \mathrm{SD}(\mu \mathrm{g} / \mathrm{g})$ dry $\mathrm{wt})$} \\
\cline { 2 - 4 } & Medium-size $(34)^{\mathrm{a}}$ & Small $(13)$ & All samples $(47)$ \\
\hline $\mathrm{As}(\mathrm{III})$ & $0.93 \pm 0.64$ & $1.03 \pm 0.71$ & $0.96 \pm 0.65$ \\
$\mathrm{As}(\mathrm{V})$ & $0.13 \pm 0.17^{*}$ & $0.28 \pm 0.25^{*}$ & $0.17 \pm 0.21$ \\
DMA & $0.09 \pm 0.10$ & $0.09 \pm 0.10$ & $0.09 \pm 0.10$ \\
MMA & $0.17 \pm 0.25$ & $0.12 \pm 0.15$ & $0.15 \pm 0.23$ \\
AsB & $1.94 \pm 1.09(19)^{\mathrm{a}}$ & $2.02 \pm 0.60(7)^{\mathrm{a}}$ & $1.96 \pm 0.97(26)^{\mathrm{a}}$ \\
Inorganic As & $1.06 \pm 0.74$ & $1.31 \pm 0.90$ & $1.13 \pm 0.79$ \\
Total As & $7.62 \pm 4.10^{*}$ & $10.71 \pm 6.10^{*}$ & $8.48 \pm 4.87$ \\
Inorganic & $14.0 \pm 27.01$ & $12.13 \pm 6.82$ & $13.50 \pm 6.94$ \\
$\quad$ As/total & & & \\
$\quad$ As $(\%)$ & & & \\
Organic & $48.25 \pm 16.74$ & $44.85 \pm 16.43$ & $47.33 \pm 16.40$ \\
$\quad$ As $/$ total & & & \\
$\quad$ As $(\%)$ & & & \\
\hline
\end{tabular}

${ }^{a}$ The number inside the parenthesis denotes the sample number.

b Inorganic As is the summation of $\mathrm{As}(\mathrm{III})$ and $\mathrm{As}(\mathrm{V})$.

${ }^{\mathrm{c}}$ Organic As is the summation of DMA, MMA and AsB.

${ }^{*} p$ value $\leqslant 0.05$.

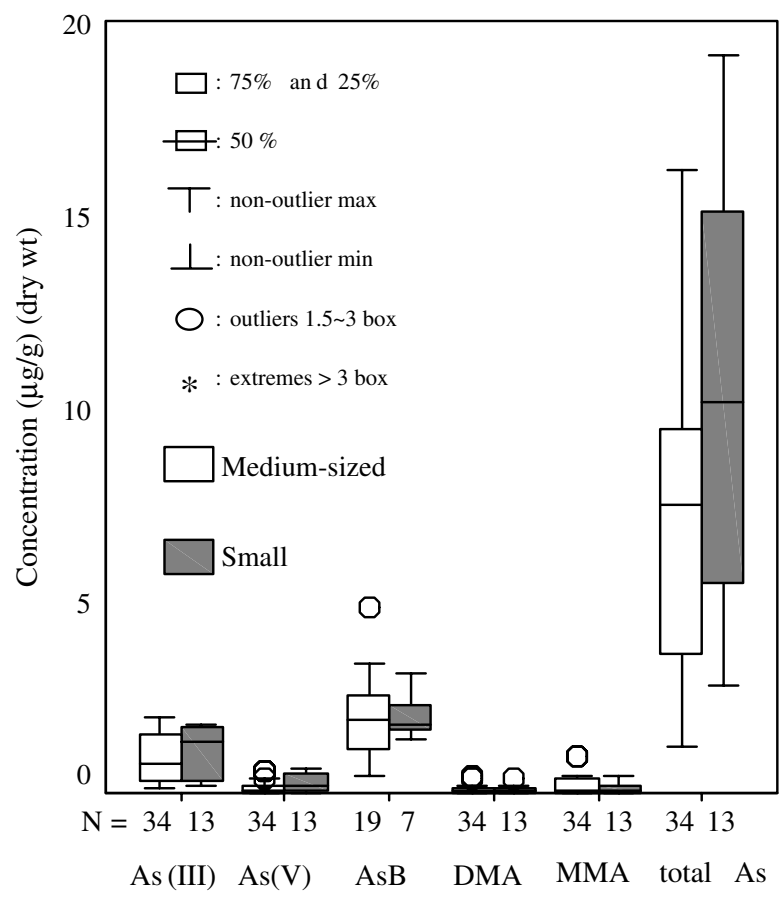

Fig. 2. Distributions of concentrations of total As and various As species in clams.

farmed clams is not linearly related to the exposure environment. Table 2 presents the bio-concentration factor (BCF) of total As content in clams from sediment and pond water. The $\mathrm{BCF}$ from sediment ranges from 0.74 to 0.35 and the $\mathrm{BCF}$ from pond water ranges from 363.8 to 164.5. The BCF at an equilibrium, of internal biota concentration to exposure concentration, describes partitioning between exposure medium (water and sediment in this study) and clam. Few BCF measurements are available and the mechanisms that involve adsorption/desorption
Table 2

Concentrations of total As and inorganic As in sediment, pond water and clams (in dry wt)

\begin{tabular}{llll}
\hline Pond no. & Total As & & \\
\cline { 2 - 4 } & Sediment $(\mu \mathrm{g} / \mathrm{g})$ & Pond water $(\mathrm{mg} / \mathrm{l})$ & Clam $(\mu \mathrm{g} / \mathrm{g}$ \\
\hline$\# 1$ & 19.69 & 0.040 & $14.55,12.03$ \\
$\# 2$ & 45.60 & 0.097 & $18.51,15.96$ \\
$B C F^{\mathrm{a}}$ & & & \\
$\# 1$ & $0.74,0.61$ & $363.8,300.8$ & \\
$\# 2$ & $0.41,0.35$ & $190.8,164.5$ & \\
$A s(I I I)$ & & & $1.67,1.80$ \\
$\# 1$ & 1.08 & $\mathrm{ND}$ & $1.73,1.28$ \\
$\# 2$ & 0.59 & $\mathrm{ND}$ & $0.46,0.58$ \\
$A s(V)$ & & & $0.52,0.27$ \\
$\# 1$ & 15.0 & 0.035 & \\
$\# 2$ & 41.8 & 0.082 & \\
\hline
\end{tabular}

${ }^{\text {a }} \mathrm{BCF}=($ total As contents in clams $) /($ total As contents in sediment or pond water).

in sediment are complex. Accordingly, the inter relationship of As content in clams to that in sediment and pond water is unable to be determined. McGeer et al. (2003) found an inverse relationship between $\mathrm{BCF}$ and the concentrations of metals in the aquatic environment. Additionally, the metal BCFs derived from sediment studies tend to be orders of magnitude lower that those from aquatic (McGeer et al., 2003). In our results, the ratios of BCF derived from pond water and sediment of two ponds are 492.3 and 467.5, respectively. The present study also reveals that exposure to an environment with high As results in low $\mathrm{BCF}$ and vice versa. The adoption of $\mathrm{BCF}$ as an indicator of the long-term hazard potential was due to the sparse data on the chronic toxicity of As for clam. As such, BCF is of most value when limited data are available (OECD, 2001).

Inorganic $\mathrm{As}(\mathrm{V})$ species predominate in sediment and pond water, whereas organic As species predominate in clams because of methylation in organisms. When ingesting, clams simultaneously suck sediment and pond water with large amounts of $\mathrm{As}(\mathrm{V})$. In the methylation of organisms, $\mathrm{As}(\mathrm{V})$ is first transformed to $\mathrm{As}(\mathrm{III})$. The $\mathrm{As}(\mathrm{III})$ is present in clams apparently at the beginning of methylation (Shiomi et al., 1996).

Total As content in clams varies from $0.21 \mu \mathrm{g} / \mathrm{g}$ (wet wt) to $3.25 \mu \mathrm{g} / \mathrm{g}$ (wet wt) in this work. This range is wider than that the normal As content in blue mussels obtained through the monitoring program in Norway $(1.3-2.8 \mu \mathrm{g} / \mathrm{g}$ wet wt) (Airas et al., 2004) and in Mid-Atlantic (USA) (0.93-1.53 $\mu \mathrm{g} / \mathrm{g}$ wet wt) (Greene and Crecelius, 2006).

To compare with our results associated with As species in oysters (Crassostrea gigas) (Liu et al., 2006), the DMA content exceeds the As(III) and MMA contents in oysters, whereas the As(III) content exceeds those of the DMA and MMA in clams. The inorganic As content in oysters is $1.64 \%$ of the total As content, while that in clams is $13.5 \%$ of the total As content. Edmonds and Francesconi (1993), Munoz et al. (1999, 2000) and Li et al. (2003) 
documented a similar situation that inorganic As content in clams or mussels exceeds those in other bivalve animals, such as oysters, scallops and others. It is highest in clams. Farmed oysters generally live in shallow oceans in racks, far from sediment, whereas clams usually live at the bottom of a pond with sandy sediment. The large amount of inorganic As in pond sediment directly enters the clams. Additionally, arsenobetaine is a common metabolism product in mussels. Arsenobetaine content normally ranges from 1 to $100 \mu \mathrm{g} / \mathrm{g}$ (dry wt) and vary widely (Cullen and Nelson, 1993; Gailer et al., 1995; Larsen, 1995; Súñer et al., 2002). In our works, the mean ratios of AsB contents to total As contents in oysters and clams are $49.5 \%$ and $41.1 \%$, respectively. Súñer et al. (2002) found that the average AsB content in clams was $20.2 \mu \mathrm{g} / \mathrm{g}$ (dry wt), which was approximately $46 \%$ of the total As content. The ratio herein is close to that of Súñer et al. (2002).

\subsection{Potential carcinogenic risks to human health by ingestion}

Although the As(V) contents of small clams differ significantly from that of medium-sized clams, the inorganic As contents do not differ significantly. Thus, inorganic As data for both small and medium-sized clams were combined to evaluate potential risks. The inorganic As content followed a log-normal distribution as determined by performing a $\mathrm{K}-\mathrm{S}$ test, and a geometric average and a geometric standard deviation were obtained from the log-normal distributions before an MC simulation was implemented. Five thousand data on the concentration of inorganic As were generated by MC simulation based on observed data to quantify the uncertainty in the evaluated parameters. Fig. 3 shows the simulated frequency of inorganic As content in clams. Based on field observations, the inorganic As content in clams is generally predicted to fall between the 5th and 95th percentiles. Traditionally, the 5th, 25th, 50th, 75th, and 95th percentiles of risk are employed to assess likelihoods of exceeding risk levels (Han et al.,

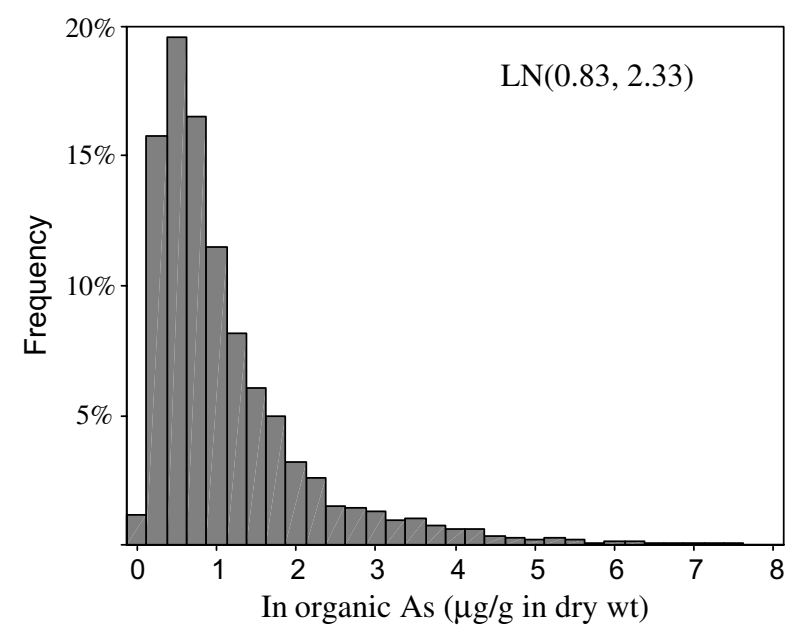

Fig. 3. Simulated 5000 data on inorganic As contents in clams.

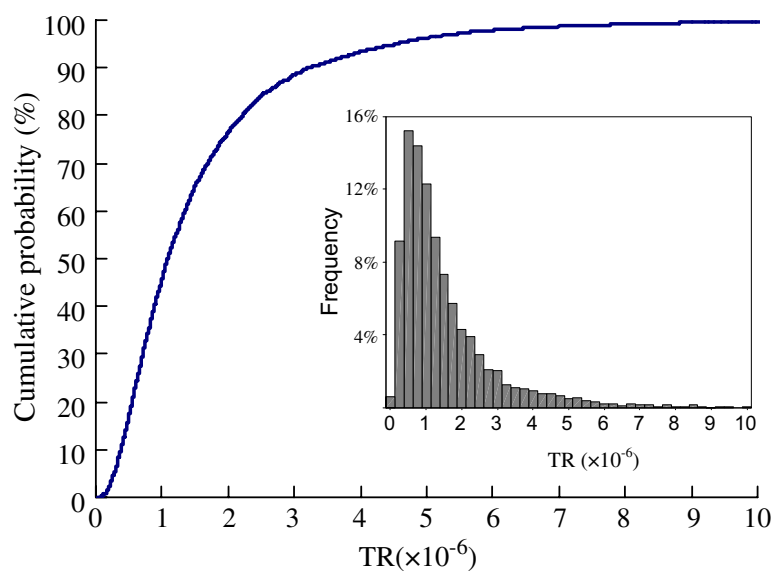

Fig. 4. Cumulative probability and frequency of TR.

2000; Liao and Ling, 2003; Jang et al., 2006). The TRs calculated from the 5th, 25th, 50th, 75th, and 95th percentiles are $0.28 \times 10^{-6}, 0.63 \times 10^{-6}, 1.09 \times 10^{-6}, 1.93 \times 10^{-6}$ and $4.52 \times 10^{-6}$, respectively (Fig. 4). The first two TRs below one millionth are at a safe level, while the remaining TRs of over one millionth only slightly exceed the acceptable risk standard. However, Shih (2001) used questionnaire method to survey the ingestion rates for adult consumption of cultured shellfish in Taiwan. The shellfish ingestion rate ranged from 4 to $14.5 \mathrm{~g}$ /day-person. Using 4 and 14.5 $\mathrm{g} /$ day-person as the ingestion rates of clam, the 95th percentiles of TRs are $22.3 \times 10^{-6}$ and $80.7 \times 10^{-6}$, respectively, which largely exceed the accepted risk standard $\left(10^{-6}\right)$.

The use of different methods for estimating ingestion rates may be responsible for the large difference in the assessed risks. Using an ingestion rate estimated from the annual production of clams and the population in Taiwan, such as in this study, Wu et al. (1999) and Jang et al. (2006) gave an average ingestion rate of seafood. Using a questionnaire, as done by Shih (2001), Karen et al. (2003), Liao and Ling (2003) and Liu et al. (2006), can yield a range of ingestion rates of seafood. The former is an objective method, but does not yield the variation. The latter is a subjective method, but provides the information on the variation. In this study, both average consumption method and the questionnaire method are used to derive the ingestion rates of clams and estimate the corresponding potential health risks.

Liu et al. (2006) presented risks of $12.6-38.2 \times 10^{-6}$ at the 95th percentile associated with the ingestion of inorganic As in oyster in the BFD area. An average ratio of inorganic As content to total As content in clams, $13.50 \%$, significantly exceeds that of oysters, $1.64 \%$, revealing that the exposure to inorganic As in clams due to ingestion exceeds that in oysters by over eight times. However, the various ingestion rates of their edible portion influence the calculation of risks. For example, the risk of cancer associated with ingesting clams of $0.812 \mathrm{~g} /$ day-person is smaller than that associated with ingesting oysters of 
$18.6 \mathrm{~g} /$ day-person $\left(4.52 \times 10^{-6}\right.$ versus $\left.12.6 \times 10^{-6}\right)$ while the risk of cancer associated with ingesting clams of $14.5 \mathrm{~g} /$ day-person is much higher than that associated with ingesting oysters of $18.6 \mathrm{~g} /$ day-person $\left(80.7 \times 10^{-6}\right.$ versus $12.6 \times 10^{-6}$ ).

If a 95th percentile TR value of $10^{-6}$ is an acceptable risk, then the corresponding recommended daily ingestion rate of clam can be calculated by Eq. (1). The inorganic As concentration (mean $\pm \mathrm{SD}$ ) $1.13 \pm 0.79 \mu \mathrm{g} / \mathrm{g}$ (dry wt) in clam is used, and the calculated safe daily ingestion rate of clam is $0.18 \mathrm{~g}$. This is about one fifteenth of the mass of clam in a clam soup. Restated people in Taiwan should eat no more than two times of clam soup per month to have an acceptable health cancer risk $\left(10^{-6}\right)$ from exposure to inorganic arsenic through clam consumption.

\section{Conclusions}

This work studies total As and As species contents in clams farmed in BFD hyperendemic areas of southwestern Taiwan. Average total As contents in medium-sized and small clams were 7.62 and $10.71 \mu \mathrm{g} / \mathrm{g}$ (dry wt), respectively, and the As content in clams varied widely. The arsenic species considered herein represented around $61 \%$ of total As content. Average ratios of inorganic As content to total As content in clams ranged from $12.3 \%$ to $14.0 \%$ and significantly exceeded those in oysters, indicating that ingestion by human beings is responsible for high exposures to As if a same daily ingestion rate was applicable to both clam and oyster. The risk assessment input parameters can be varied, either through sensitivity testing or through application of the probabilistic risk assessment technique, to account for a variety of circumstances and uncertainties. The results of the risk assessment indicate that potential carcinogenic risks associated with consumption of clams from the BFD area ranging from slightly $\left(4.52 \times 10^{-6}\right)$ to largely $\left(80.7 \times 10^{-6}\right)$ exceed the acceptable target risk. The results reveal that people who consume a large quantity of clams farmed in the BFD region are exposed to a serious threat to their health. Furthermore, given that the BFD area has numerous types of seafood contaminated with As, the monitoring safety of the consumption of seafood is important to establish the degree to which these risks result from the aquacultural needs of BFD regions. The results may prompt a new focus on the consumption of aquacultured fish and shellfish research in BFD regions by highlighting the life history and behavioral information most relevant to evaluating a shellfish's susceptibility to inorganic As.

\section{Acknowledgement}

The authors thank the National Science Council of the Republic of China for financially supporting this research under Contracts Nos. NSC90-2313-B-002-322 and NSC91-2313-B-002-270.

\section{References}

Airas, S., Duinker, A., Julashamn, K., 2004. Copper, zinc, arsenic, cadmium, mercury, and lead in blue mussels (Mytilus edulis) in the Bergen Harbor Area, Western Norway. Bull. Environ. Contam. Toxicol. 73, 276-284.

Alberti, J., Rubio, R., Rauret, G., 1995. Extraction method for arsenic speciation in marine organisms. Fresen. J. Anal. Chem. 351, 420-425.

Baudrimont, M., Schäfer, J., Marie, V., Maury-Brachet, R., Bossy, C., Boudou, A., Blanc, G., 2005. Geochemical survey and metal bioaccumulation of three bivalve species (Crassostrea gigas, Cerastoderma edule and Ruditapes philippinarum) in the Nord Médoc salt marshes (Gironde estuary, France). Sci. Tot. Environ. 337, 265-280.

Boyden, C.R., 1977. Effect of size upon metal content of shellfish. J. Mar. Biol. Assoc. UK 57, 675-714.

Ch'i, I.C., Blackwell, R.Q., 1968. A controlled retrospective study of blackfoot disease, an endemic peripheral gangrene disease in Taiwan. Am. J. Epidemiol. 88, 7-24.

Cullen, W.R., Nelson, J.C., 1993. The biotransformation, of monomethylarsonate and dimethylarsinate into arsenobetaine in seawater and mussels. Appl. Organomet. Chem. 7, 319-327.

Dagnac, T., Padro, A., Rubio, R., Rauret, G., 1999. Speciation of arsenic in mussels by the coupled system liquid chromatography UV irradiation hydride generation inductively coupled plasma mass spectrometry. Talanta 48, 763-772.

Edmonds, J.S., Francesconi, K.A., 1993. Arsenic in seafoods: human health aspects and regulations. Mar. Pollut. Bull. 26, 665-674.

Gailer, J., Francesconi, K.A., Edmonds, J.S., Irgolic, K.J., 1995. Metabolism of arsenic compounds by the blue mussel Mytilus edulis after accumulation from seawater spiked with arsenic compounds. Appl. Organomet. Chem. 9, 341-355.

Geiszinger, A., Goessler, W., Kuehnelt, D., Francesconi, K., Kosmus, W., 1998. Determination of arsenic compounds in earthworms. Environ. Sci. Technol. 32, 2238-2243.

Greene, R., Crecelius, E., 2006. Total and inorganic arsenic in MidAtlantic marine fish and shellfish and implication to fish advisories. Int. Environ. Assess. Manage. 2 (4), 344-354.

Han, B.C., Jeng, W.L., Hung, T.C., Ling, Y.C., Shieh, M.J., Chien, L.C., 2000. Estimation of metal and organochlorine pesticide exposures and potential health threat by consumption of oysters in Taiwan. Environ. Pollut. 109, 147-156.

Huang, Y.K., Lin, K.H., Chen, H.W., Chang, C.C., Liu, C.W., Yang, M.H., Hsueh, Y.M., 2003. Arsenic species contents at aquacultural farm and in farmed mouthbreeder (Oreochromis mossambicus) in blackfoot disease hyperendemic areas. Food Chem. Toxicol. 41, 14911500 .

Jang, C.S., Liu, C.W., Lin, K.H., Huang, F.M., Wang, S.W., 2006. Spatial analysis of potential carcinogenic risks associated with ingesting arsenic in aquacultural tilapia (Oreochromis mossambicus) in blackfoot disease hyperendemic areas. Environ. Sci. Technol. 40, 1707-1713.

Karen, H.W., Frank, W.D., Arunthavarani, T., William, R.H., Albert, E.H., 2003. Fish tissue quality in the lower Mississippi River and health risks from fish consumption. Sci. Tot. Environ. 302, 109-126.

Lai, V.W.M., Cullen, W.R., Ray, S., 1999. Arsenic speciation in scallops. Mar. Chem. 66, 81-89.

Larsen, E.H., 1995. Speciation of dimethylarsinyl-riboside derivatives (arsenosugars) in marine reference materials by HPLC-ICP-MS. Fresen. J. Anal. Chem. 352, 582-588.

Liao, C.M., Ling, M.P., 2003. Assessment of human health risks for arsenic bioaccumulation in tilapia (Oreochromis mossambicus) and large-scale mullet (Liza macrolepis) from blackfoot disease area in Taiwan. Arch. Environ. Contam. Toxicol. 45, 264-272.

Li, W., Chao, W., Chao, Z., Hulle, M.V., Cornelis, R., Zhang, X., 2003. A survey of arsenic species in chinese seafood. Food Chem. Toxicol. 41, $1103-1110$

Liu, C.W., Huang, F.M., Hsueh, Y.M., 2005. Revised cancer risk assessment of inorganic arsenic upon consumption of tilapia 
(Oreochromis mossambicus) from blackfoot disease hyperendemic areas. Bull. Environ. Contam. Toxicol. 74, 1037-1044.

Liu, C.W., Liang, C.P., Huang, F.M., Hsueh, Y.M., 2006. Assessing the human health risks from exposure of inorganic arsenic through oyster (Crassostrea gigas) consumption in Taiwan. Sci. Tot. Environ. 361, 5766.

McGeer, J.C., Brix, K.V., Skeaff, J.M., Deforest, D.K., Brigham, S.I., Adams, W.J., Green, A., 2003. Inverse relationship between bioconcentration factor and exposure concentration for metals: implications for hazard assessment of metals in the aquatic environment. Environ. Toxicol. Chem. 22, 1017-1037.

Munoz, O., Velez, D., Montoro, R., 1999. Optimization of the solubilization, extraction and determination of inorganic arsenic $[\mathrm{As}(\mathrm{III})+\mathrm{As}(\mathrm{V})]$ in seafood products by acid digestion, solvent extraction and hydride generation atomic absorption spectrometry. Analyst. 124, 601-607.

Munoz, O., Devesa, V., Suner, M.A., Velez, D., Montoro, R., Urieta, I., Macho, M.L., Jalon, M., 2000. Total and inorganic arsenic in fresh and processed fish products. J. Agric. Food Chem. 48, 4369-4376.

OECD, 2001. Harmonized integrated hazard classification system for human health and environmental hazards of chemical substances and mixtures. Annex 2. Guidance Document 27, ENV/JM/MONO 8.OECD, Paris, France.

Oremland, R.S., Stotlz, J.F., 2003. The ecology of arsenic. Science 300, 939-944.

Shih, L.Y., 2001. Web education on the environmental contamination and health risk assessment - examples of heavy metals and aquacultures products. MS thesis, Dept. of Public Health, Taipei Medical University, Taipei, Taiwan.

Shiomi, K., Suglyama, Y., Shimakura, K., Nagashima, Y., 1996. Retention and biotransformation of arsenic compounds administered intraperitoneally to carp. Fish. Sci. 62, 261-266.

Súñer, M.A., Devesa, V., Clemente, M.J., Vélez, D., Montoro, R., Urieta, I., Jalón, M., Macho, M.L., 2002. Organoarsenical species contents in fresh and processed seafood products. J. Agric. Food. Chem. 50, 924 932.

Taiwan COA, 2003. Taiwanese Food Supply and Demand Annual Report; Council of Agriculture, Executive Yuan. Taiwan.

Taiwan DOH, 2003. Health and National Health Insurance Annual Statistics Information Service; Department of Health, Executive Yuan. Taiwan. $<$ http://www.doh.gov.tw/statistic/index.htm $>$.

Taiwan DOH, 2006. Health and National Health Insurance Annual Statistics Information Service; Department of Health, Executive Yuan. Taiwan. $<$ http://www.doh.gov.tw/statistic/index.htm $>$.

Taiwan DOS, 2004. MOI Statistical information Service; Department of Statistical, Ministry of the Interior, Taiwan. $<$ http://www.moi.gov.tw/ stat $>$.

Tseng, W.P., 1977. Effects and dose-response relationships of skin cancer and blackfoot disease with arsenic. Environ. Health Persp. 19, 109119.

Ünlü, M.Y., Fowler, S.W., 1979. Factors affecting the flux of arsenic through the mussel (Mytilus galloprovincialis). Mar. Biol. 51, 209219.

US EPA, 1988. Special report on ingested inorganic arsenic: Skin cancer; nutritional essentiality. EPA/625/3-87/013, US Environmental Protection Agency, Risk Assessment Forum, Washington, DC.

US EPA, 1989. Guidance manual for assessing human health risks from chemically contaminated, fish and shellfish. EPA-503/8-89-002, US Environmental Protection Agency, Washington, DC.

US EPA, 2001. Risk assessment guidance for superfund, vol. 3, part A. Process for conducting probabilistic risk assessment. Office of Emergency and Remedial Response, Washington, DC.

US EPA, 2006. Risk-based concentration table, Region 3, US Environmental Protection Agency. Philadelphia, PA. <http://www.epa.gov/ reg3hwmd/risk/human/index.htm>.

Wu, S.J., Chang, Y.H., Fang, C.W., Pan, W.H., 1999. Food sources of weight, calories, and three macro-nutrients-NAHSIT 1993-1996. Nutr. Sci. J. 24, 41-58. 